Gasoline, being a fuel endowed with special properties, rarely acts as a substitute for other fuels and for this reason supplies only 'legitimate' markets. Fuel oil, however, is at the present time supplying 'illegitimate' markets, that is, markets where its peculiar properties as a liquid fuel are not a real asset and where the solid fuel, coal, is in every way satisfactory; the irrational treatment of coal is probably the most potent single factor in the disorganisation of the petroleum industry as a whole.

With the advent of the cracking process, liquid fuel became a raw material for the production of gasoline. Cracking plants were installed which enabled. gasoline to be produced at a cost price of not more than 3 cents above the price of the raw material used. Similarly, the price of fuel oil automatically dropped owing to excessive production and the consequent necessity for securing markets irrespective of their financial value and suitability. Long-term contracts were negotiated at low prices and the industry is thus still compelled to produce more crude oil than is economically desirable in order to meet such 'illegitimate' demands.

The coal industry, which is the other main source of the world's fuel supply, has been materially affected not only by this unjustifiable competition of liquid fuel, but also by the fact that authorities in coalproducing countries have deemed it necessary to tax gasoline. Thus it is that the beneficial effects of years of continued research into the economic production of gasoline have been practically annihilated and attention has perforce been focused on the expensive process of hydrogenation of coal and lignite, and on cheaper alternative fuels. In the latter connexion, authorities anticipating a reduction in revenue from gasoline have imposed taxes on Diesel oils and other fuels which, if their development were unhampered, would automatically raise the general standards of living. It is therefore apparent that the great excess of fuel oil has, by facilitating the production of cheap gasoline, helped to build up a system of taxation which is restricting the marvellous economic developments of the age.

From a detailed study of modern methods of refining crude oil, it is apparent that there are several methods by which the present excessive production of fuel oil may be curtailed. Theoretically, the maximum reduction of 86 per cent is obtainable by cracking all straight-run fuel oil to coke; by a combination of hydrogenation and cracking, a reduction of $70 \cdot 5$ per cent can be secured; by cracking all straight-run fuel by composite residue and non- residue processes, a reduction of 47 per cent is possible and, finally, by cracking all straight-run fuel by the low level (liquid residue) system, a reduction of 30 per cent is obtainable. Not only are there these savings of fuel oil production, but also in each case a conservation of the world's crude oil supply would automatically accrue. Each of these four systems has its specific advantages and disadvantages, but it is suggested that by cracking all straight-run fuel by current methods, that is, residue and nonresidue processes, much would be achieved towards the ultimate balance of production with legitimate demand in so far as fuel oil is concerned. This system would doubtless have to be modified to meet the demand for gas oil, Diesel oil, etc., and partial change towards the other possible processes might prove essential. Fundamentally, however, it is free from appreciable defects and its advantages are considerable.

Omission to provide part of the liquid fuel at present marketed would immediately raise fuel oil prices to a reasonably remunerative level. Much illegitimate fuel oil business would return to coal. There would be a cessation of any real or apparent justification for the restrictive measures enforced by coal-producing countries and less inducement for producers to seek such abnormal outlets as coal hydrogenation for their products.

Supplies of fuel being limited, its use would be restricted to those applications where its special properties are of real value. By permitting the oil industry a reasonable return for its produce and labour, the consumer would be guaranteed a supply of petroleum products of the constantly improving quality rendered necessary by modern progress in engine design. Moreover, the life of crude oil resources would definitely be prolonged. It is true that such a reorganisation would involve a moderate capital expenditure on additional cracking equipment, but this would be offset by direct savings in production and drilling costs. The difficulties involved in the successful application of this scheme are primarily operative, and not due to the fundamental composition of cracked fuel ; their solution, therefore, must be entrusted to the technologists of the industry.

Summarily, conservation of crude oil has already paved the way towards the balance between production and consumption of petroleum but, unaided by rationalisation on the lines indicated above, it cannot restore the industry to prosperity, and just so soon as this balance is achieved in respect of fuel oil, so soon will the industry emerge from the present chaos.

\title{
Annual Conference of the Museums Association
}

\footnotetext{
THE forty-fourth annual conference of the Museums Association was held at Norwich on July 3-7, when one hundred and eighty members of the Association met under the presidency of Sir Henry Miers.

The prevailing financial conditions, which prevented some municipalities from sending delegates, were responsible for a somewhat smaller attendance than usual, but the Conference atoned for this by the unusual diversity of subjects on the programme and the vigour of the subsequent discussions, while the social side was reduced to a minimum and each of the receptions afforded an opportunity of seeing one of Norwich's museums or some feature of scientific or artistic importance.
}

In his fifth presidential address, Sir Henry Miers gave an encouraging account of the Association's work in many fields, at home and abroad, during the past year. Despite the difficulty of the times, the Association is holding its own with regard to membership, while its importance and usefulness are increasing markedly throughout the museum world. The Empire survey has been completed by Mr. Markham's tour of Australasian museums and Dr. Bather's and Mr. Sheppard's visit to the West Indies. At home the most important advance has been the strengthening of the Association at its new headquarters, Chaucer House.

Reviewing the events of the last five years in his capacity as president, Sir Henry referred to the great 
debt the Association owes to the Carnegie Corporation of New York which has made the Empire surveys possible, and the Carnegie United Kingdom Trustees, who have co-operated with the Association in trying to improve local museums in Great Britain. He referred to the usefulness of the Regional Federations which now number six, and he believes they are powerful factors in the effective development of the new museum service.

Museums continue to increase in number and in size, and Sir Henry reported that since 1928 the total number of museums in Great Britain has increased from 530 to 578. Unfortunately, in the problem of the curator little change has taken place. A very useful survey might be made of the immediate effect produced by the appointment of a qualified curator. Sir Henry regrets that very little has been accomplished with regard to the extension of the influence of museums into rural districts or with the much. discussed establishment of so-called folk museums. Although there still exist defects in museum service, he feels there has also been a great advance.

Other matters of importance with which Sir Henry dealt were co-operation with the British Broadcasting Corporation; and the usefulness of temporary art exhibitions in small museums. In commenting upon the continued value of the Museums Journal, Sir Henry referred to the great services rendered by its retiring editor, Dr. F. A. Bather.

Following the presidential address, Mr. F. Leney, curator of the Norwich museums, gave a talk, illustrated by lantern slides, on the main features of the collections in his care and their arrangement. He directed particular attention to the avoidance of reflections in plate glass.

For the remainder of the morning the delegates heard the reflections of the Empire survey secretary, Mr. S. F. Markham, on the conclusion of his seven years' experience in visiting museums in Great Britain and other countries. $\mathrm{He}$ is particularly concerned with the financial grants made by councils or other bodies to their museums and gave an analytical list of the most generous and the poorest areas; with methods of exhibition of art and antiquities; and with publications for the visitor. As Mr. Markham has probably seen more museums than any other one man, his remarks were most valuable, although often very unflattering, to the home curator and museum.

Wednesday was devoted to the discussion of art problems. Mr. Eric Brown of the National Gallery of Canada, Ottawa, spoke on Canadian art and pointed out that Canada's first art school predated any of England's by a generation, and Mr. H. M. Hake described recent extensions at the National Portrait Gallery. The remainder of the morning was occupied by an animated discussion on provincial art galleries, opened by Major A. A. Longden. A great variety of suggestions was made for brightening these, including local exhibits; freedom of action for the director; brighter interiors with music, flowers and first class refreshment facilities.

In the afternoon, Prof. W. G. Constable gave his views on training for museum work based on his year's experience as director of the Courtauld Institute, and pointed out how far the Institute could assist museum curators. He was followed by Dr. H. J. Plenderleith who discussed some problems respecting water-colours and inks, and gave an account as satisfactorily practical as Prof. Constable's was theoretical.
Most of Thursday morning was devoted to the annual business meeting, but the delegates welcomed Dr. Robert Gurney who opened a discussion on the illustration of natural science. He pleaded for more exhibits illustrating life-histories and evolution, and thinks that the great importance of insects should be much more strongly stressed. The subsequent discussion showed that whatever may be wrong with museums it is not for lack of ideas in curators. In the next paper Miss Delia Griffin, of the Children's Museum, Hartford, United States, gave a talk on children's museums, in which she said the idea was to make the museum a sort of club which the children felt belonged to them. She has found that, at first, natural history specimens prove more attractive than artistic objects.

Further contributions to the natural history side were made in the afternoon by Mr. H. J. Howard of Norwich, who spoke on "Nature Study and the Child", and by Mr. Colin Matheson of the National Museum of Wales, who gave many good hints on exhibits of invertebrate animals. Afterwards, Dr. R. T. Gunther made many practical suggestions for emphasising the human side of collections and it was encouraging to learn how far curators are endeavouring to tell the public something of the lives of the men associated with the objects they show.

Practically the whole of Friday was taken up by excursions. On Friday evening, however, the Conference closed with a most interesting lecture, illustrated by cinematograph films, by Lord William Percy on the Bittern in Norfolk.

\section{University and Educational Intelligence}

Cambridge.-An important change in the regulations for Part II of the Natural Sciences Tripos (physics and chemistry) has been announced, to talke effect in 1934. Under the new regulations, there will be four papers in chemistry; two of a general nature and two more specialised, including questions in inorganic, organic, theoretical and physical chemistry, colloid science, metallurgy, and crystal chemistry. A sufficient number of questions will be set for a candidate to attain a first class in one or more of the sub-divisions. Four papers will also be set in physics, three being of a general nature. The fourth paper will contain specialised questions on some branches of physics, but a sufficient number of questions on crystallography and crystal physics will be set in this paper to allow a candidate to gain full marks by answering questions on these branches only.

Mr. Leslie Howarth, of Gonville and Caius College, Cambridge, has been awarded the Busk studentship in aeronautics for 1933-34. The studentship was founded in memory of Edward T. Busk who lost his life in 1914 while flying an experimental aeroplane.

London.-Prof. H. W. Florey, since 1931 Joseph Hunter professor of pathology in the University of Sheffield, has been appointed to the Sir William Dunn chair of pathology tenable at Guy's Hospital Medical School.

The following degrees have recently been awarded: D.Sc. in zoology to Mr. K. G. Blair (Birkbeck College) for published papers on the "Taxonomy of various Families of Coleoptera, more especially of the Series Heteromera"; D.Sc. 